Literature Reviews

\title{
Improving Organizational Citizenship Behavior through Spirituality and Work Engagement
}

\author{
${ }^{1}$ Aminah Ahmad and ${ }^{2}$ Zoharah Omar \\ ${ }^{I}$ Institute for Social Science Studies, Universiti Putra Malaysia, Selangor, Malaysia \\ ${ }^{2}$ Department of Professional Development and Continuing Education, \\ Faculty of Educational Studies, Universiti Putra Malaysia, Selangor, Malaysia
}

\author{
Article history \\ Received: 22-09-2014 \\ Revised: 08-10-2014 \\ Accepted: 20-04-2015 \\ Corresponding Author: \\ Aminah Ahmad \\ Institute for Social Science \\ Studies, Universiti Putra \\ Malaysia, Selangor, Malaysia \\ Email: aminahahmad49@gmail.com
}

\begin{abstract}
The focus of previous studies on predictors of organizational citizenship behavior has been on individual, organizational and task characteristics as well as leadership behaviors. Despite the greater focus of previous studies on individual characteristics, little is known about the potential effect of spirituality on organizational citizenship behavior. Using the work engagement model and results from previous empirical studies, a framework was developed to examine the effect of workplace spirituality on organizational citizenship behavior through work engagement as the mediator. It is expected that workplace spirituality will have positive effects on organizational citizenship behavior and work engagement and work engagement will positively affect organizational citizenship behavior. According to the framework, when employees experience workplace spirituality, their engagement in work roles will be enhanced and they will be more likely to engage in citizenship behavior. The significance of this paper is that it offers a framework as well as hypotheses that could be tested and the framework implies that organizations should establish climates that are spiritually-rich, recognizing the potential predictive ability of workplace spirituality on organizational citizenship behavior and work engagement.
\end{abstract}

Keywords: Workplace Spirituality, Work Engagement, Organizational Citizenship Behaviour

\section{Introduction}

\section{Background of Study}

Organizational Citizenship Behavior (OCB), has been a subject of focus by researchers due to increasing evidence of OCB's impact on organizational and individual performance (Dunlop and Lee, 2004; Podsakoff et al., 2009). OCB has the potential to increase organization efficiency by enhancing employee task performance and productivity (e.g., Organ, 1997; Podsakoff et al., 2000). According to Organ et al. (2006), when experienced employees voluntarily help new employees learn the ropes it enables the employees to become productive employees faster, thus improving the efficiency of the work team. Besides improving work efficiency, OCB may also help to increase the stability of organizational performance. For example, conscientious employees tend to maintain a consistently high output level, hence reducing variability in a work team's performance. Furthermore, organizational effectiveness may be enhanced when OCB exists through the creation of social capital (e.g., social capital is enhanced through the strengthening of network ties when employees exhibit helping behavior, resulting in improvement of information transfer and organizational learning and effective execution of organizational activities) (Organ et al., 2006). Other outcomes of OCB at the organizational level include reduced costs and customer satisfaction (Podsakoff et al., 2009). Besides organizational outcomes, OCB is related to individual level outcomes, including managerial assessment of employee performance, decisions on reward allocation and various withdrawal-related factors such as absenteeism, employee turnover intention and actual turnover (Podsakoff et al., 2009).

Recognizing the association of OCB with organizational and individual outcomes, researchers have investigated antecedents of OCB. Podsakoff et al. (2000) noted that most research on OCB have focused on four major categories of antecedents comprising of individual characteristics, organizational characteristics, job 
characteristics and leadership behaviours. Of these, Somech and Drach-Zahavy (2004) emphasized that greater attention has been given to individual characteristics. An individual's characteristics are expected to affect the extent to which the individual will go above and beyond that which has been stipulated in the job description. A meta-analysis conducted by Organ and Ryan (1995) revealed that some of the individual factors that have been found to influence OCB include job attitudes (job satisfaction, organizational commitment, perceived fairness, leader supportiveness), role perceptions (role conflict and role ambiguity) and personality traits (conscientiousness, agreeableness, positive affectivity and negative affectivity). Later, a meta-analysis by LePine et al. (2002) on OCB studies similarly found that besides antecedents such as satisfaction, commitment, fairness and leader support, conscientiousness as an individual characteristic has often been examined by researchers in studies on predictors of OCB. Despite the greater focus of previous studies on individual characteristics, little is known about the potential effect of spirituality on OCB. For example, Sulea et al. (2012) have studied the role of work engagement as a mediator between workplace resource and extra-role behavior such as OCB. However, they have focused on perceived organizational support as a workplace resource. Workplace spirituality which involves employees' experience of finding ultimate meaning in work and sense of connectedness with organizational members (Gupta et al., 2013) began to be viewed as a new perspective towards understanding employee behavior including OCB and hence improve organizational performance. Among the limited studies that had examined the link between spirituality and OCB are those by (Nasurdin et al., 2013; Kazemipour et al., 2012) who found significant correlations between spirituality and OCB. Considering studies on the spirituality-OCB link is limited, this paper intends to propose a framework on the effect of workplace spirituality, as an individual resource, on OCB and the mediating role of work engagement using the work engagement model by Bakker and Demerouti (2008) and previous empirical literature. It addresses the need to integrate workplace spirituality and work engagement with organizational behavior, namely $\mathrm{OCB}$, in a framework which could be used by researchers to better understand OCB. It is hoped that the framework developed in this paper would add to the scarcity of literature on how workplace spirituality is linked to OCB through work engagement. It would help organizations in understanding the role of spirituality and work engagement in enhancing employee OCB that would ultimately help improve organizational performance.

\section{Organizational Citizenship Behavior}

Organ (1988) defined OCB as "an individual's behaviour in the workplace that is discretionary and not directly or explicitly recognized by the formal reward system and that in the aggregate promotes the effective functioning of the organization". Based on this definition, there are three critical aspects of OCB. First, OCB is thought of as a discretionary behavior, which is not part of the employee's job description and the employee engages in it out of personal choice. Second, OCB goes above and beyond that which has been stipulated in the job description. Third, OCB contributes to overall organizational effectiveness. Later, Organ (1997) redefined OCB as any behavior that contributes to the social as well as psychological context supporting task performance. OCB has also been defined as any non-task related behavior that contributes to the achievement of organizational goals by improving its social and psychological environments (Rotundo and Sackett, 2002). According to Organ (1988), OCB is comprised of five dimensions namely, (1) altruism (e.g., assisting coworkers who have heavy workloads), (2) conscientiousness (e.g., work attendance beyond the norm), (3) sportsmanship (e.g., not complaining about trivial matters), (4) courtesy (e.g., consulting with coworkers before taking action) and (5) civic virtue (e.g., involvement in the political process within the organization). A meta-analysis of the literature by LePine et al. (2002) revealed that this five-dimension framework by Organ (1988) has been widely used by researchers in numerous empirical studies. Podsakoff and MacKenzie (1994) defined OCB as an individual's extra-role behavior at work that is not explicitly acknowledged by a formal reward system of the organization. OCB is context-bound since this behavior is more likely to be generated in a culture which places collective interest ahead of the individual (Gautam et al., 2005; Moorman and Blakely, 1995; Paine and Organ, 2000). This OCB characteristic has been studied and endorsed by Cohen and Avrahami (2006) who found that collectivist employees tend to engage in OCB more often than individualistic employees.

\section{Workplace Spirituality}

Workplace spirituality refers to "the recognition that employees have an inner life that nourishes and is nourished by meaningful work that takes place in a community" (Ashmos and Duchon, 2000). An employee seeks meaningful work, not only a paycheck and attempts to be a whole person, connected to their true self, to others at work and to the transcendent (Hudson, 2014). Spirituality experienced by an employee involves a common connectedness and togetherness with other colleagues at work (Gupta et al., 2013), or the sharing and experiencing of common attraction, attachment and togetherness with others at the workplace (Harrington, 2004). Three dimensions of workplace spirituality, "meaningful work" (individual level), "sense of community" (group level) and "alignment with 
organizational values" (organization level), were identified and measured by Milliman et al. (2003).

According to Adams and Csiernik (2002), "workplace spirituality involves positively sharing, valuing, caring, respecting, acknowledging and connecting the talents and energies of people in a meaningful goal-directed behavior that enables them to belong, be creative, be personally fulfilled and take ownership in their combined destiny" (p. 43). Giacalone and Jurkiewicz (2003), who emphasized on values and sense of community, defined workplace spirituality as "a framework of organizational values evidenced in the culture that promotes employees' experience of transcendence through the work process, facilitating their sense of being connected to others in a way that brings feelings of completeness and joy" ( $p$. 13). An extended definition of the construct was provided by Marques (2005) who defined workplace spirituality as "an experience of interconnectedness and trust among those involved in a work process, engendered by individual goodwill, leading to the collective creation of a motivational organizational culture, epitomized by reciprocity and solidarity; and resulting in enhanced overall performance, which is ultimately translated in lasting organizational excellence" (p. 283). There seems to be various definitions of workplace spirituality and lack of agreement on an appropriate definition. However, Duchon and Plowman (2005) concluded that a majority of the definitions of workplace spirituality involve the elements of sense of meaning, purpose and connectedness.

Unlike the previous view which regards spirituality and management as incompatible, the present view has changed whereby both these factors are seen as linked and additionally, researchers and practitioners now realize that supporting workplace spirituality can to a certain extent help improve employee performance (James et al., 2011). Several scholars suggest that besides improving performance, spirituality can result in higher productivity, increased problem solving capabilities, better decisionmaking, higher intuitive capabilities, greater creativity and more efficient utilization of resources (Weitz et al., 2012). If managed appropriately, workplace spirituality could serve as a mechanism for controlling employee behaviour at work (James et al., 2011).

\section{Work Engagement}

In the literature, work engagement has been defined by a number of academicians and researchers. One of the first definitions that was published in the literature was by Kahn (1990) who studied the psychological conditions of engagement. According to Kahn (1990), engagement refers to "the harnessing of organization members' selves to their work roles; in engagement, people employ and express themselves physically, cognitively and emotionally during role performances" (p. 694). It is the "simultaneous employment and expression of a person's 'preferred self' in task behaviors that promote connections to work and to others, personal presence (physical, cognitive and emotional) and active, full role performance" (p. 700). Rothbard (2001) noted that there were two important motivational components of role engagement-attention and absorption in a role. Engaged employees possess high levels of energy and are enthusiastic and often fully immersed in their work such that time appears to fly (Bakker and Demerouti, 2008).

When employees are engaged in role performance, they invest their hands, head and heart (Rich et al., 2010) and are psychologically present when performing an organizational role (Kahn, 1990; 1992). When employees are psychologically present, they are focused, attentive, connected and integrated in role performance (Kahn, 1992). In addition, there is a variation in the extent to which employees retain their selves within the role that they perform (Kahn, 1990).

Schaufeli et al. (2002) defined engagement "as a positive, fulfilling, work-related state of mind that is characterized by vigor, dedication and absorption" ( $p$. 74). Vigor is associated with high energy levels and mental resilience while at work; dedication refers to a state of being strongly involved in work and accompanied by feelings of enthusiasm and significance as well as a sense of challenge; and absorption refers to a state of being in full concentration and engrossed in work or unable to detach oneself from work. They further added that engagement is "a more persistent and pervasive affective-cognitive state that is not focused on any particular object, event, individual, or behavior" (p. 74).

\section{Work Engagement Model}

According to the work engagement model by Bakker and Demerouti (2008), job resources in the form of, for example, social support from coworkers and supervisors, feedback for performance improvement, skill variety and autonomy initiate a motivational process leading to greater work engagement and consequently to improved performance. Job resources refer to physical, social, psychological or organizational elements of a job which decreases job demands; stimulate the achievement of work goals and/or personal growth, learning and development (Schaufeli and Bakker, 2004). Personal resources refer to individuals' sense of ability to successfully control and produce an impact on their environment and such resources are positive self-evaluations that are associated with resiliency (Hobfoll et al., 2003). It has been shown that positive self-evaluations predict desirable outcomes such as motivation, goal setting, performance and job and life satisfaction (Judge et al., 2004). In addition, 
the model proposes that job resources become more significant and increase their motivational potential in situations where there are high job demands such as workload and emotional and mental demands. Job and personal resources have been shown to be mutually related and personal resources can act as independent predictors of work engagement (Xanthopoulou et al., $2009 \mathrm{a} ; 2009 \mathrm{~b})$. Based on the model of work engagement, it is postulated that a personal resource such as spirituality can predict work engagement and consequently lead to OCB.

\section{Workplace Spirituality and Organizational Citizenship Behavior}

Workplace spirituality is one of the variables that has so far been ignored in organizational behaviour research and it has a great possibility of influencing OCB. Tepper (2003) in his conceptual framework pointed out that employees who have high spiritual values and experience a greater meaning at work are likely to perform frequent acts of OCB. Additionally, Tan and Geh (2009) proposed a theoretical model in which work spirituality has been linked to OCB and they have verified it empirically. Kazemipour et al. (2012) who conducted a study on 305 Iranian nurses employed in four public hospitals, concluded that workplace spirituality dimensions (i.e., a sense of community, meaningful work and alignment with organisational values) have significant associations with OCB and workplace spirituality accounted for $16 \%$ of the variation in OCB of nurses. Nasurdin et al. (2013) investigated the effects of workplace spirituality dimensions on OCB of academic staff attached to 15 private institutions of higher learning in Malaysia. They found that meaningful work, as a dimension of spirituality, was positively related to all of the OCB dimensions (conscientiousness, sportsmanship, helping behaviour and civic virtue). Similarly, a significant relationship between workplace spirituality and OCB was found in studies among teachers in Iran (Ahmadi et al., 2014; Moosapour et al., 2013). Hence, empirical studies suggest that employees with a deep sense of meaning and feel connected to others at work and experience a strong sense of alignment with organizational values are bound to display OCB. We therefore postulate that workplace spirituality would positively affect OCB.

\section{Workplace Spirituality and Job Engagement}

Currently, both workplace spirituality and job engagement are emerging as important topics in the field of organizational behaviour with a focus on employee performance and well-being as outcomes. Earlier, Mirvis (1997) noted that to engage an employee at work one should bear in mind the employee's spiritual life and collective potential. According to Giacalone and Jurkiewicz (2010), the possibility of having more determination and greater attempt to exert more effort at work is more common among employees who consider their work as a means to develop spirituality than those who work only for the sake of money. Similarly, Krishnakumar and Neck (2002) suggested that organizations with spiritually-rich values are more effective in engaging the souls of their employees than organizations with less spiritual values (Jurkiewicz and Giacalone, 2004). Krishnakumar and Neck (2002) noted that fostering spirituality will generate the feeling of wholeness among employees when they come to work. According to Kahn (1992), both workplace spirituality and engagement involve one's complete self in performing one's work role.

As yet, empirical research linking workplace spirituality to work engagement is still lacking and only a few studies have considered the effect of spirituality on work engagement at the workplace. For instance, Kolodinsky et al. (2008) found that organizational spirituality was positively linked to work engagement. Likewise, the results of a study by Saks (2011) showed that meaningfulness of work, which is a dimension of workplace spirituality, is a significant psychological condition that influences an employee's degree of engagement at work. When work is seen as fulfilling and satisfying, striving for task accomplishment takes on new meaning resulting in greater investment of energy and time or engagement at work (Giacalone and Jurkiewicz, 2010; Paloutzian and Lowe, 2012). Similarly, other researchers have also shown the association between meaningfulness of work and work engagement (Hirschi, 2012; Rothmann and Buys, 2011).

In conclusion, even though spirituality in the workplace and work engagement have previously been more often studied separately, there are some evidence that workplace spirituality might be an important new driver of work engagement.

\section{Work Engagement and Organization Citizenship Behaviour}

According to Kahn (1992), an individual becomes actively engaged at work when he or she is able to involve and express himself or herself physically, cognitively and emotionally. He noted that it is this involvement and expression of oneself in task behaviors that promote role performance. Rana et al. (2014) proposed a theoretical model of antecedents and outcomes of employee engagement in which OCB is one of the organizational outcomes of engagement. Similarly, Soane et al. (2012) suggested that OCB is a possible outcome of job engagement because the engaged state not only encompasses positive affect but also motivates beneficial behaviors. Hence, it is 
reasonable to expect that work engagement could lead to role behavior such as OCB. Past studies have shown the relationship between work engagement and OCB. According to a study in Norway by Kuvaas and Dysvik (2009), employees who engage in collaborative work are more involved in OCB. Rurkkhum and Bartlett (2012), in their study conducted in Thai organizations, revealed that there was a positive relationship between employee engagement and every component of OCB including courtesy, conscientiousness, altruism, sportsmanship and civic virtues. Other studies have also reported the link between work engagement and OCB (Hakanen et al., 2006; 2008). Engaged employees tend to perform OCB because they efficiently achieve their goals at work and they feel that they are able to perform OCB as an extrarole behavior (Christian et al., 2011). It can be concluded that the literature seems to support the influence of work engagement on OCB.

\section{Framework on Spirituality, Work Engagement and $O C B$}

Using the work engagement model (Bakker and Demerouti, 2008) and previous literature, a framework was developed to explain the relationships between workplace spirituality, work engagement and OCB (Fig. 1). The work engagement model offers a useful theoretical framework for understanding how an affective-motivational state, that is work engagement, serves as a mechanism through which a personal resource such as employee workplace spirituality is linked to employee performance such as OCB. Studies have shown that when employees are provided with resources, they experience work engagement, which in turn will result in positive outcomes such as commitment (Hakanen et al., 2006; Hu and Schaufeli, 2011) and proactive behavior (Salanova and Schaufeli, 2008). Spirituality is a type of personal resource (Bickerton et al., 2014; Karakas, 2010) where it is seen as a means for employees to cope with their work as they feel related to their work and find their work as meaningful to them. Based on the work engagement model, individual resources, such as spirituality at workplace, could generate positive behavior in the form of OCB. When employees experience transcendence through the work process and a sense of being connected to others in the organization they experience positive emotions that bring feelings of joy and completeness. Based on the Broaden and Build theory (Fredrickson, 2003), these emotions generate an array of thinking and acting, such as engaging in OCB which involves for example helping their colleagues or the work team with heavy workload.

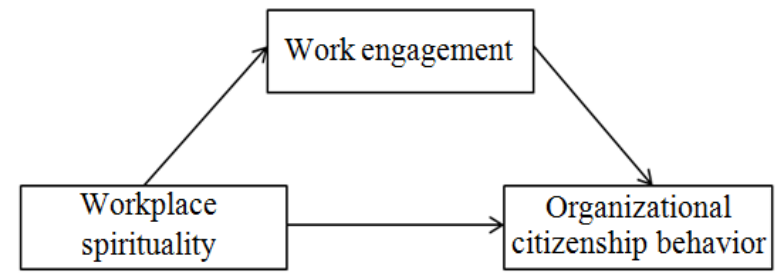

Fig. 1. Framework of the mediating effect of work engagement on the relationship between workplace spirituality and organizational citizenship behavior

Employees who find their work meaningful or have a sense of purpose in their work are also able to integrate their personal lives with their work and hence experience wholeness. Such employees are likely to be more engaged in their work whereby according to Bakker (2011), they are physically, cognitively and emotionally immersed in their work and this in turn will result in improved performance including the engagement in citizenship behavior at work.

Based on the framework developed the following hypotheses were formulated:

- H1: Workplace spirituality is positively related to OCB

- H2: Workplace spirituality is positively related to work engagement

- H3: Work engagement is positively related to OCB

- H4: Work engagement mediates the relationship between workplace spirituality and OCB

\section{Conclusion}

Using the work engagement model by Bakker and Demerouti (2008) and results from previous studies, a research framework was developed on the relationship between workplace spirituality and organizational citizenship behavior with work engagement as the mediator. Besides using the work engagement model, the framework integrates literature on the different topics of workplace spirituality, employee engagement and OCB. Recognizing workplace spirituality's potential to stimulate work engagement which in turn generates OCB, can help organizations realize the importance of spirituality as an individual resource that could improve OCB through work engagement. If organizations allow employees to be whole persons at work through the experience of meaningful work, connectedness with others at work and a strong alignment of their values with organizational values, there is a great possibility that both the employees and the organizations would benefit. The significance of this paper is that it offers a framework as well as hypotheses that could be tested using structural equation modelling procedure. At the same time this paper proposed that the work engagement model by Bakker and Demerouti (2008) can be used to 
explain the interrelationships among workplace spirituality, work engagement and OCB. Besides, the proposed framework is a response to the call for demonstrating the utility of workplace spirituality as asserted by Giacalone and Jurkiewicz (2010), "identifying the practical implications of workplace spirituality is perhaps the most fundamental method of demonstrating utility. Researchers must show how spiritual variables impact work-related processes" (p. 9).

\section{Acknowledgement}

The authors would like to acknowledge the Ministry of Education, Malaysia for funding this work (Project No. 06-01-13-1181FR) through the Fundamental Research Grant Scheme.

\section{Author's Contributions}

All authors equally contributed to this work.

\section{Ethics}

The authors confirm that this work is original and has not been published elsewere.

\section{References}

Adams, D.W. and R. Csiernik, 2002. Seeking the lost spirit: Understanding spirituality and restoring it to the workplace. Employee Assistance Q., 17: 31-44. DOI: $10.1300 / J 022$ v17n04_03

Ahmadi, S., Y. Nami and R. Barvarz, 2014. The Relationship between spirituality in the workplace and organizational citizenship behavior. ProcediaSocial Behavioral Sci., 114: 262-264.

DOI: 10.1016/j.sbspro.2013.12.695

Ashmos, D. and D. Duchon, 2000. Spirituality at work. J. Managerial Inquiry, 9: 134-145. DOI: $10.1177 / 105649260092008$

Bakker, A.B. and E. Demerouti, 2008. Towards a model of work engagement. Career Develop. Int., 13: 209-223. DOI: 10.1108/13620430810870476

Bakker, A.B., 2011. An evidence-based model of work engagement. Current Directions Psychol. Sci., 20: 265-269. DOI: 10.1177/0963721411414534

Bickerton, G.R., M.H. Miner, M. Dowson and B. Griffin, 2014. Spiritual resources and work engagement among religious workers: A three-wave longitudinal study. J. Occupat. Organiz. Psychol., 87: 370-391. DOI: 10.1111/joop.12052

Christian, M.S., A.S. Garza and J.E. Slaughter, 2011. Work engagement: A quantitative review and test of its relations with task and contextual performance. Personnel Psychol., 64: 89-136. DOI: $10.1111 / \mathrm{j} .1744-6570.2010 .01203 . \mathrm{x}$
Cohen, A. and A. Avrahami, 2006. The relationship between individualism, collectivism, the perception of justice, demographic characteristics and organisational citizenship behaviour. Service Industries J., 26: 889-901. DOI: $10.1080 / 02642060601011707$

Duchon, D. and D.A. Plowman, 2005. Nurturing the spirit at work: Impact on work unit performance. Leadership Q., 16: 807-833. DOI: $10.1016 /$ j.leaqua.2005.07.008

Dunlop, P.D. and K. Lee, 2004. Workplace deviance, organizational citizenship behavior and business unit performance: The bad apples do spoil the whole barrel. J. Organiz. Behavior, 25: 67-80. DOI: $10.1002 /$ job. 243

Fredrickson, B., 2003. The value of positive emotions. Am. Sci., 91: 330-335. DOI: 10.1511/2003.4.330

Gautam, T., R. Van Dick, U. Wagner, N. Upadhyay and A.J. Davis, 2005. Organizational citizenship behavior and organizational commitment in Nepal. Asian J. Social Psychol., 8: 305-314. DOI: 10.1111/j.1467-839X.2005.00172.X

Giacalone, R.A. and C.L. Jurkiewicz, 2003. Right from wrong: The influence of spirituality on perceptions of unethical business activities. J. Bus. Ethics, 46: 85-97. DOI: 10.1023/A:1024767511458

Giacalone, R.A. and C.L. Jurkiewicz, 2010. Toward a Science of Workplace Spirituality. In: Handbook of Workplace Spirituality and Organizational Performance, Giacalone, R.A. and C.L. Jurkiewicz (Eds.), Shubhi Publications, Gurgaon, ISBN-10: 8188817058, pp: 3-26.

Gupta, M., V. Kumar and M. Singh, 2013. Creating satisfied employees through workplace spirituality: A study of the private insurance sector in Punjab (India). J. Bus. Ethics, 122: 1-10. DOI: $10.1007 / \mathrm{s} 10551-013-1756-5$

Hakanen, J.J., A.B. Bakker and W.B. Schaufeli, 2006. Burnout and work engagement among teachers. J. School Psychol., 43: 495-513. DOI: $10.1016 /$ j.jsp.2005.11.001

Hakanen, J.J., W.B. Schaufeli and K. Ahola, 2008. The job demands-resources model: A three-year crosslagged study of burnout, depression, commitment and work engagement. Work Stress, 22: 224-241. DOI: $10.1080 / 02678370802379432$

Harrington, A., 2004. Hope rising out of despair: The spiritual journey of patients admitted to a hospice. J. Religious Gerontol., 16: 123-145. DOI: 10.1300/J078v16n03_09

Hirschi, A., 2012. Callings and work engagement: Moderated mediation model of work meaningfulness, occupational identity and occupational self-efficacy. J. Couns. Psychol., 59: 479-485. DOI: 10.1037/a0028949 
Hobfoll, S.E., R.J. Johnson, N. Ennis and A.P. Jackson, 2003. Resource loss, resource gain and emotional outcomes among inner city women. J. Personality Social Psychol., 84: 632-643. DOI: $10.1037 / 0022-3514.84 .3 .632$

$\mathrm{Hu}$, Q. and W.B. Schaufeli, 2011. Job insecurity and remuneration in Chinese family-owned business workers. Career Develop. Int., 16: 6-19. DOI: $10.1108 / 13620431111107784$

Hudson, R., 2014. The question of theoretical foundations for the spirituality at work movement. J. Manage., Spirituality Relig., 11: 27-44. DOI: $10.1080 / 14766086.2013 .801031$

James, M.S., A.K. Miles and T. Mullins, 2011. The interactive effects of spirituality and trait cynicism on citizenship and counterproductive work behaviors. J. Manage., Spirituality Relig., 8: 165-182. DOI: $10.1080 / 14766086.2011 .581814$

Judge, T.A., A.E. Van Vianen and I.E. De Pater, 2004. Emotional stability, core self-evaluations and job outcomes: A review of the evidence and an agenda for future research. Human Performance, 17: 325-346. DOI: 10.1207/s15327043hup1703_4

Jurkiewicz, C.L. and R.A. Giacalone, 2004. A values framework for measuring the impact of workplace spirituality on organizational performance. J. Bus. Ethics, 49: 129-142. DOI: 10.1023/B:BUSI.0000015843.22195.b9

Kahn, W.A., 1990. Psychological conditions of personal engagement and disengagement at work. Acad. Manage. J., 33: 692-724. DOI: 10.2307/256287

Kahn, W.A., 1992. To be fully there: Psychological presence at work. Hum. Relations, 45: 321-349. DOI: $10.1177 / 001872679204500402$

Karakas, F., 2010. Spirituality and performance in organizations: A literature review. J. Bus. Ethics, 94: 89-106. DOI: 10.1007/s10551-009-0251-5

Kazemipour, F., S. Mohamad Amin and B. Pourseidi, 2012. Relationship between workplace spirituality and organizational citizenship behavior among nurses through mediation of affective organizational commitment. J. Nurs. Scholarship, 44: 302-310. DOI: $10.1111 /$ j.1547-5069.2012.01456.x

Kolodinsky, R.W., R.A. Giacalone and C.L. Jurkiewicz, 2008. Workplace values and outcomes: Exploring personal, organizational and interactive workplace spirituality. J. Bus. Ethics, 81: 465-480. DOI: $10.1007 / \mathrm{s} 10551-007-9507-0$

Krishnakumar, S. and C.P. Neck, 2002. The "what", "why" and "how" of spirituality in the workplace. J. Managerial Psychol., 17: 153-164. DOI: $10.1108 / 02683940210423060$

Kuvaas, B. and A. Dysvik, 2009. Perceived investment in permanent employee development and social and economic exchange perceptions among temporary employees. J. Applied Social Psychol., 39: 2499-2524. DOI: $10.1111 / \mathrm{j} .1559-1816.2009 .00535 . \mathrm{x}$
LePine, J.A., A. Erez and D.E. Johnson, 2002. The nature and dimensionality of organizational citizenship behavior: A critical review and metaanalysis. J. Applied Psychol., 87: 52-65. DOI: $10.1037 / 0021-9010.87 .1 .52$

Marques, J., 2005. HR's crucial role in the establishment of spirituality in the workplace. J. Am. Acad. Bus., 7: 27-31.

Milliman, J., A.J. Czaplewski and J. Ferguson, 2003. Workplace spirituality and employee work attitudes: An exploratory empirical assessment. J. Organiz. Change Manage., 16: 426-447. DOI: $10.1108 / 09534810310484172$

Mirvis, P.H., 1997. "Soul Work" in organizations. Organiz. Sci., 8: 192-206. DOI: 10.1287/orsc.8.2.192

Moorman, R.H. and G.L. Blakely, 1995. Individualismcollectivism as an individual difference predictor of organizational citizenship behavior. J. Organiz. Behavior, 16: 127-142. DOI: 10.1002/job.4030160204

Moosapour, S., M. Feizi and H. Alipour, 2013. Spiritual intelligence relationship with organizational citizenship behavior of high school teachers in Germi city. J. Bus. Manage. Social Sci. Res., 2: 72-75.

Nasurdin, A.M., M. Nejati and Y.K. Mei, 2013. Workplace spirituality and organizational citizenship behaviour: Exploring gender as a moderator. South Afr. J. Bus. Manage., 44: 61-74.

Organ, D.W. and K. Ryan, 1995. A meta-analytic review of attitudinal and dispositional predictors of organizational citizenship behavior. Personnel Psychol., 48: 775-802. DOI: $10.1111 / \mathrm{j} .1744-6570.1995 . t b 01781 . x$

Organ, D.W., 1988. Organizational Citizenship Behavior: The Good Soldier Syndrome. 1st Edn., Lexington Books, Lexington, ISBN-10: 0669117889, pp: 132.

Organ, D.W., 1997. Organizational citizenship behavior: It's construct clean-up time. Hum. Perform., 10: 85-97. DOI: 10.1207/s15327043hup1002_2

Organ, D.W., P.M. Podsakoff and S.B. MacKenzie, 2006. Organizational citizenship Behavior: Its Nature, Antecedents and Consequences. 1st Edn., SAGE Publications, Thousand Oaks, ISBN-10: 0761929967, pp: 350 .

Paine, J.B. and D.W. Organ, 2000. The cultural matrix of organizational citizenship behavior: Some preliminary conceptual and empirical observations. Hum. Resource Manage. Rev., 10: 45-59. DOI: 10.1016/S1053-4822 (99) 00038-8

Podsakoff, N.P., S.W. Whiting, P.M. Podsakoff and B.D. Blume, 2009. Individual-and organizational-level consequences of organizational citizenship behaviors: A meta-analysis. J. Applied Psychol., 94: 122-141. DOI: 10.1037/a0013079

Podsakoff, P.M. and S.B. MacKenzie, 1994. Organizational citizenship behaviors and sales unit effectiveness. J. Market. Res., 3: 351-363. DOI: $10.2307 / 3152222$ 
Podsakoff, P.M., S.B. MacKenzie, J.B. Paine and D.G. Bachrach, 2000. Organizational citizenship behaviors: A critical review of the theoretical and empirical literature and suggestions for future research. J. Manage., 26: 513-563.

DOI: $10.1177 / 014920630002600307$

Paloutzian, R.F. and D.A. Lowe, 2012. Spiritual Transformation and Engagement in Workplace Culture. In: Psychology of Religion and Workplace Spirituality. Peter C. Hill and B. Dik (Eds.), IAP, Charlotte, N.C., ISBN-10: 161735662X, pp: 180-199.

Rana, S., A. Ardichvili and O. Tkachenko, 2014. A theoretical model of the antecedents and outcomes of employee engagement: Dubin's method. J. Workplace Learn., 26: 249-266. DOI: 10.1108/JWL-09-2013-0063

Rich, B.L., J.A. Lepine and E.R. Crawford, 2010. Job engagement: Antecedents and effects on job performance. Acad. Manage. J., 53: 617-635. DOI: 10.5465/AMJ.2010.51468988

Rothbard, N.P., 2001. Enriching or depleting? The dynamics of engagement in work and family roles. Administrative Sci. Q., 46: 655-684. DOI: $10.2307 / 3094827$

Rothmann, S. and C. Buys, 2011. Job demands and resources, psychological conditions, religious coping and work engagement of reformed church ministers. J Psychol. Afr., 21: 173-185. DOI: 10.1080/14330237.2011.10820446

Rotundo, M. and P.R. Sackett, 2002. The relative importance of task, citizenship and counterproductive performance to global ratings of job performance: A policy-capturing approach. J. Applied Psychol., 87: 66-80.

DOI: $10.1037 / 0021-9010.87 .1 .66$

Rurkkhum, S. and K.R. Bartlett, 2012. The relationship between employee engagement and organizational citizenship behaviour in Thailand. Hum. Resource Develop. Int., 15: 157-174.

DOI: $10.1080 / 13678868.2012 .664693$

Saks, A.M., 2011. Workplace spirituality and employee engagement. J. Manage. Spirituality Relig., 8: 317-340. DOI: $10.1080 / 14766086.2011 .630170$

Salanova, M. and W.B. Schaufeli, 2008. A crossnational study of work engagement as a mediator between job resources and proactive behaviour. Int. J. Hum. Resource Manage., 19: 116-131.

DOI: $10.1080 / 09585190701763982$

Schaufeli, W.B. and A.B. Bakker, 2004. Job demands, job resources and their relationship with burnout and engagement: A multi-sample study. J. Organiz. Behavior, 25: 293-315. DOI: 10.1002/job.248
Schaufeli, W.B., M. Salanova, V. González-Romá and A.B. Bakker, 2002. The measurement of engagement and burnout: A two sample confirmatory factor analytic approach. J. Happiness Stud., 3: 71-92. DOI: 10.1023/A:1015630930326

Soane, E., C. Truss, K. Alfes, A. Shantz, C. Rees and M. Gatenby, 2012. Development and application of a new measure of employee engagement: The ISA engagement scale. Hum. Resource Develop. Int., 15: 529-547. DOI: 10.1080/13678868.2012.726542

Somech, A. and A. Drach-Zahavy, 2004. Exploring organizational citizenship behaviour from an organizational perspective: The relationship between organizational learning and organizational citizenship behaviour. J. Occupational Organiz. Psychol., 77: 281-298.

DOI: 10.1348/0963179041752709

Sulea, C., D. Virga, L.P. Maricutoiu, W. Schaufeli, C.Z. Dumitru and F.A. Sava, 2012. Work engagement as mediator between job characteristics and positive and negative extra-role behaviors. Career Develop. Int., 17: 188-207.

DOI: $10.1108 / 13620431211241054$

Tan, G. and E. Geh, 2009. Spirituality at work and OCB: An examination of the mediation effect of organizational commitment. Proceedings of the 8th Asian Conference and 1st MENA Conference of the Academy of HRD, (CAH' 09), Research Collection Lee Kong Chian School of Business.

Tepper, B.J., 2003. Organisational Citizenship Behaviour and the Spiritual Employee. In: Handbook of Workplace Spirituality and Organizational Performance, Giacalone, R.A. and C.L. Jurkiewicz (Eds.), Shubhi Publications, Gurgaon, ISBN-10: 8188817058, pp: 181-190.

Weitz, E., Y. Vardi and O. Setter, 2012. Spirituality and organizational misbehavior. J. Manage., Spirituality Relig., 9: 255-281. DOI: $10.1080 / 14766086.2012 .730782$

Xanthopoulou, D., A.B. Bakker, E. Demerouti and W.B. Schaufeli, 2009a. Reciprocal relationships between job resources, personal resources and work engagement. J. Vocational Behav., 74: 235-244. DOI: $10.1016 /$ j.jvb.2008.11.003

Xanthopoulou, D., A.B. Bakker, E. Demerouti and W.B. Schaufeli, 2009b. Work engagement and financial returns: A diary study on the role of job and personal resources. J. Occupat. Organiz. Psychol., 82: 183-200. DOI: 10.1348/096317908X285633 